through upregulating cellular activities involving iNOS-presenting macrophages and $B$ cell receptor signaling, which may be associated with the pathogenesis of P.g.-triggered RA.

REFERENCES:

[1] Jenning M, Marklein B, Ytterberg J, et al. Bacterial citrullinated epitopes generated by Porphyromonas gingivalis infection-a missing link for ACPA production. Ann Rheum Dis 2020;79:1194-202.doi:10.1136/ annrheumdis-2019-216919

Disclosure of Interests: None declared

DOI: 10.1136/annrheumdis-2021-eular.3998

\section{POS0403 \\ RISK FACTORS FOR PROGRESSION OF RHEUMATOID ARTHRITIS-ASSOCIATED INTERSTITIAL LUNG DISEASE: REASSURING IMPACT OF METHOTREXATE}

C. Lucas ${ }^{1}$, A. Tremblay ${ }^{1}$, S. Jouneau ${ }^{2}$, A. Perdriger ${ }^{1} .{ }^{1} \mathrm{CHU}$, Rheumatology, Rennes, France; ${ }^{2} \mathrm{CHU}$, Pneumology, Rennes, France

Background: Factors associated with rheumatoid arthritis-associated interstitial lung disease (RA-ILD) progression and prognosis are not well identified, especially the impact of methotrexate.

Objectives: Identify risk factors of ILD progression in RA-ILD patients in a longitudinal study.

Methods: RA patients with ILD confirmed in 2 high resolution computed tomography $(\mathrm{HRCT})$ chest scans spaced at least 6 months apart (TO: date of the first HRCT chest scan describing ILD; Tx: date of the last HRCT chest scan available) were consecutively included in this retrospective multi-centric study from 2010 to 2020. HRCT chest scans were analyzed for each patient at T0 and Tx by 2 independent radiologists to determinate ILD pattern (definite UIP, probable UIP, indeterminate UIP, non-UIP) and progression during the follow-up including variation of the fibrosis score (aggravated or non-aggravated). Characteristics of patients (demographic-clinical-biological findings, respiratory function tests, and treatments exposure) at ILD diagnosis and during the follow-up (TO-Tx) were analyzed as potential determinants of ILD progression through multivariable logistic regression analysis. Overall survival was analyzed using Kaplan-Meier method. Results: 74 RA-ILD patients were included. During a mean duration between T0-Tx of 2.8 years $\pm 2.4,26$ patients $(35 \%)$ had ILD progression. Thirty-three patients (45\%) were treated by methotrexate at ILD diagnosis (T0) and 29 of them (39\%) continued methotrexate during T0-Tx. Logistic regression in multivariate analysis revealed that a treatment by methotrexate at ILD diagnosis was protective against ILD progression $(O R=0.14$ [0.04-0.52]; $p=0.0031)$. Non-UIP pattern at ILD diagnosis was also protective against ILD progression (OR=0.09 [0.02-0.36]; $p=0.0005$ ). The follow-up for survival analysis was 5.1 years \pm 2.9 . Thirty-three patients (31\%) died, and the 3 -year survival rate was $80 \%$. Survival was better for non-aggravated ILD patients ( $\mathrm{HR}=3.5$ [1.46-8.4]; $\mathrm{p}=0.004)$ and for patients treated by methotrexate during T0-Tx $(H R=0.36[0.15-0.84] ; p=0.018)$ and worse for definite UIP patterns ( $H R=2.570$ [1.078-6.128]; $p=0.0332)$.

Conclusion: In RA-ILD patients, non-UIP pattern and methotrexate treatment are associated with better ILD evolution and prognosis.

Disclosure of Interests: None declared

DOI: 10.1136/annrheumdis-2021-eular.4157

\section{Spondyloarthritis - aetiology, pathogenesis and animal models}

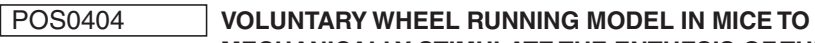 MECHANICALLY STIMULATE THE ENTHESIS OF THE ACHILLES TENDON}

A. Briolay ${ }^{1}$, S. Delplace ${ }^{2}$, F. Duboeuf ${ }^{3}$, O. Peyruchaud ${ }^{3}$, D. Magne ${ }^{1}$, L. Brizuela ${ }^{1}$, C. Bougault ${ }^{1} .{ }^{1}$ Université Claude Bernard Lyon 1, CNRS UMR 5246, Lyon, France; ${ }^{2}$ Université du Littoral-Côte d'Opale, ULR 4490, Boulogne/Mer, France; ${ }^{3}$ Faculté de Médecine Lyon Est, INSERM U1033, Lyon, France

Background: Excessive bone formation in the entheses is one of the features of peripheral spondyloarthritis. Biomechanical stress is proposed to occupy a central place in spondyloarthritis pathophysiology, but the precise molecular and cellular mechanisms underlying the pathological response of the enthesis are still largely unknown [1]. Besides, physical therapy and exercise are recommended as non-pharmacologic therapies for patients. We focused on the effect of exercising on enthesis ossification.

Objectives: We aimed to develop and characterize an in vivo model in mice to study the impact of mechanical stimulation on the enthesis of the Achilles tendon.

Methods: DBA/1 mice were subjected to voluntary running exercise by the use of activity wheels for two weeks, and compared to mice housed in standard conditions ( $n=17$ per group). The running performances were recorded.

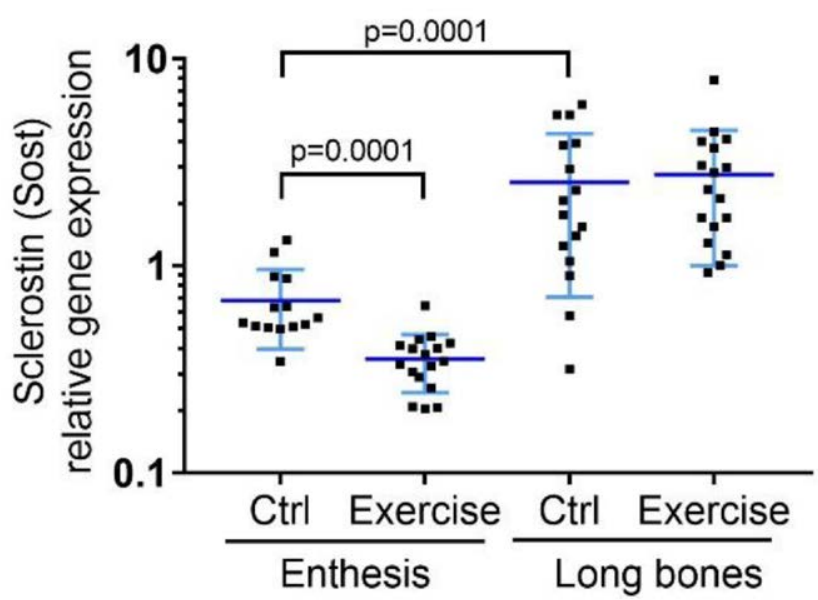

Figure 1. Expression level of the mechanosensitive gene Sclerostin (Sost). It dropped in response to exercise in entheseal tissues, but not in long bones, revealing a tissue-specific response to mechanical stimulation.

mRNAs were extracted from the long bones (flushed tibia and femur) and the ankles' entheses for real-time PCR analysis. $\mu C T$ was performed on the femurs. Alkaline phosphatase activity was detected by histology on the anchorage of the Achilles tendon to the calcaneum, and by enzymatic assay in serum samples. Luminex analysis was also conducted on serum samples for II-6 and II-8/Kc detection.

Results: Free access to the activity wheel resulted in a running exercise of $5.5 \pm 0.8 \mathrm{~km} /$ day (approximately $80 \mathrm{~km}$ in total) at $14.5 \pm 0.5 \mathrm{~m} / \mathrm{min}$. No effect was detected on the femur architecture by $\mu \mathrm{CT}$. Sclerostin (Sost) gene expression was monitored as a mechanosensitive marker. Its expression was expectedly reduced by half in entheseal tissues, but no modulation was observed in long bones (Figure 1). Similarly, exercise-induced regulation of Osterix and Runx2 expressions was observed only in enthesis samples. This tissue-specific pattern was also verified for key genes of the sphingosine-1 phosphate metabolic pathway, which we recently implicated in spondyloarthritis pathophysiology [2]. The in situ staining of alkaline phosphatase activity suggested the presence of more positive cells in the anchorage of Achilles tendon of running mice, compared to control ones. However, alkaline phosphatase activity in serum samples and its gene expression in rough tissue extracts were unchanged. No inflammatory response was detected as II-8/Kc serum levels were similar in the control and the exercising group ( $59 \pm 14$ vs $57 \pm 14 \mathrm{pg} / \mathrm{mL}$ ). In addition, II-6 was not detected in the serum and its expression was very faint and constant in the tissue extracts.

Conclusion: This work is still in progress for a more complete characterization of the model. We believe that this experimental design will be useful to study the role of mechanical stimulation specifically in the enthesis and that it can help to better understand the spondyloarthritis pathophysiology.

\section{REFERENCES:}

[1] Cambré, et al. Nat Commun, 2018; [2] El Jamal, et al. J Bone Miner Res, 2019

Acknowledgements: Société Arthritis R\&D (2020)

Disclosure of Interests: None declared

DOI: 10.1136/annrheumdis-2021-eular.833

\section{POS0405 \\ GENETIC VARIANTS WITHIN PSORIATIC ARTHRITIS (PsA)-WEIGHTED GENES FBXL19 AND HLA-B*39 MAY SERVE AS A POTENTIAL LINK BETWEEN PSA AND OBESITY}

C. Welsh ${ }^{1}$, T. Burry ${ }^{1}$, Q. Li ${ }^{1}$, A. Dohey ${ }^{1}$, D. Codner ${ }^{1}$, V. Chandran ${ }^{2,3,4}, \mathrm{D}$. D. Gladman ${ }^{3,4}$, D. O'Rielly ${ }^{1}$, P. Rahman ${ }^{2} .{ }^{1}$ Memorial University, Genetics, St. John's, Canada; ${ }^{2}$ Memorial University, Medicine, St. John's, Canada; ${ }^{3}$ Krembil Research Institute, UHN, Toronto, Canada; ${ }^{4}$ University of Toronto, Rheumatology, Toronto, Canada

Background: PsA patients have been observed to have a higher body mass index (BMI) compared to individuals with a similar disease (e.g., rheumatoid arthritis) or healthy controls ${ }^{1}$. Approximately $45 \%$ of PsA patients are considered obese with BMl's exceeding $30 \mathrm{~kg} / \mathrm{m}^{2}$, and these patients have more severe articular disease and lower response to therapy ${ }^{2}$. A recent mendelian randomization study noted that higher BMI leads to higher risk of psoriasis when using genetic variants as instrumental variables for $\mathrm{BMI}^{3}$.

Objectives: To determine if known PsA-weighted genetic variants are overrepresented in an obese population. 
Methods: 696 samples were identified from a previous genetic study in obesity where each patient was systematically examined with BMI and other related anthropometric measures were recorded. No patients had psoriasis, inflammatory arthritis or any extra-articular manifestations of spondyloarthritis. Samples were genotyped using a PsA-weighted single nucleotide polymorphism (SNP) panel, representing genetic variants associated with PsA. The cohort consisted of $73 \%$ female with an average age of 49 years \pm 15 . The average BMI of the group was $35 \pm 8 \mathrm{~kg} / \mathrm{m}^{2}$, ranging from 17 to $67 \mathrm{~kg} / \mathrm{m}^{2}$. The PSA SNP panel consists of 42 SNPs associated with PsA including IL23R, 5q31, PTPN22, TNFAIP3, HLAC, TNFRSF9, LCE3A, ADAMTS9-MAGI1, HLA-B, IL13, MICA, IL12B, ZNF8816A, TRAF3IP2, KIR2DS2, FBXL19, REL, IL23R, IL23A, TNIP1, and TYK2. DNA (10ng/ $\mathrm{uL}$ ) was used to prepare a PCR, followed by SAP, and extension reaction with Agena iPLEX Pro kit using Agena MassARRAY. Quantitative trait analysis was performed to obtain the association between BMI and genotype of the 42 SNPs using a linear regression model. Bonferroni correction was used to adjust for multiple comparisons. The factors of age, gender, smoking and height also have been adjusted in the analysis (Table 1).

Table 1. Regression analysis between BMI and 2 significant SNPs

\begin{tabular}{|c|c|c|c|c|c|c|c|c|}
\hline SNP & CHR & $\begin{array}{c}\text { Allele } \\
1\end{array}$ & $\begin{array}{c}\text { Allele } \\
2\end{array}$ & BETA & SE & $\mathbf{T}$ & $\begin{array}{c}\text { P } \\
\text { (Genotype } \\
\text { Only) }\end{array}$ & $\begin{array}{c}P \\
\text { (adjusted } \\
\text { with } \\
\text { factors) }^{*}\end{array}$ \\
\hline rs3131382 & 6 & $\mathrm{~T}$ & $\mathrm{C}$ & 2.227 & 70.7207 & 3.17 & 0.001596 & 5.40E-05 \\
\hline rs10782001 & 16 & G & A & 1.584 & 0.4347 & 3.644 & 0.00029 & 0.0007524 \\
\hline $\begin{array}{l}\text { Genotypes of } \\
\text { FBXL19 and } \\
\text { HLA-B*3905 } \\
\text { SNPs with } \\
\text { mean BMI }\end{array}$ & & & & & & & & \\
\hline SNP & rs3131382 & & & & & rs 10782001 & & \\
\hline Genotypes & $\mathrm{TT}$ & & ГC & & CC & GG & $\mathrm{GA}$ & AA \\
\hline Sample Counts & 6 & & 99 & & 575 & 75 & 324 & 246 \\
\hline $\begin{array}{l}\text { Genotype } \\
\text { Frequency }\end{array}$ & 0.0088 & & .15 & & 0.84 & 0.11 & 0.50 & 0.38 \\
\hline Mean BMI & 47.17 & & 3.73 & & 35.46 & 37.29 & 36.36 & 34.43 \\
\hline SD & 16.07 & & 64 & & 7.12 & 7.68 & 7.40 & 6.83 \\
\hline
\end{tabular}

*Adjusted for age, sex, height, and smoking

Results: Linear regression analysis with and without clinical factors for the two significant SNPs are presented in Table 1. Genotypes of two SNPs (rs10782001 and rs3131382) showed a difference with BMI (Table 1). The rs10782001 variant is within FBXL19 and the average BMI in the presence of GG genotype was 37.2 vs 34.3 for the AA genotype $(p=0.0007)$. The rs3131382 variant is within $H L A-B \star 39: 05$ and the average BMI with TT genotype was 47.1 vs 35.4 for the CC genotype $(p=0.00005)$. Both SNPs maintained significance after correction for multiple testing $(p<0.001)$.

Conclusion: Homozygotes for the minor allele of SNPs within HLA-B*39 and FBXL19 have shown to have an increased BMI, suggesting a potential genetic link between these genes and PSA and obesity. Interestingly, it has been recently noted that miR-26 suppresses adipocyte progenitor differentiation and fat production by targeting FBXL19, leading to possible biologic possibility regarding the link between PSA-weighted genetic variants and obesity ${ }^{4}$.

\section{REFERENCES:}

[1] Bhole VM et al., Rheumatology (Oxford). 2012 Mar;51(3):552-6.

[2] Klingberg E et al., Arthritis Res Ther. 2019;21(1):17.

[3] Budu-Aggrey A et al., PLoS Med. 2019 Jan 31;16(1):e1002739.

[4] Acharya A et al., Fbxl19. Genes Dev. 2019;33(19-20):1367-1380. doi:10.1101/ gad.328955.119

Disclosure of Interests: Cassidy Welsh: None declared, Tanya Burry: None declared, Quan Li: None declared, Amanda Dohey: None declared, Dianne Codner: None declared, Vinod Chandran Speakers bureau: AbbVie, Amgen, BMS, Eli Lily, Janssen, Novartis, Pfizer, UCB, Consultant of: AbbVie, Amgen, BMS, Eli Lily, Janssen, Novartis, Pfizer, UCB, Grant/research support from: AbbVie, Amgen, Eli Lily, Employee of: Spousal Employment Eli Lilly, Dafna D Gladman Speakers bureau: AbbVie, Amgen, BMS, Eli Lily, Galapagos, Gilead, Janssen, Novartis, Pfizer, UCB, Consultant of: AbbVie, Amgen, BMS, Eli Lily, Galapagos, Gilead, Janssen, Novartis, Pfizer, UC, Grant/research support from: AbbVie, Amgen, Eli Lilly, Janssen, Novartis, Pfizer, UCB, Darren O'Rielly: None declared, Proton Rahman Speakers bureau: Amgen, Abbott, AbbVie, BMS, Celgene, Eli Lily, Janssen, Novartis, Pfizer, Merck, UCB, Consultant of: Amgen, Abbott, AbbVie, BMS, Celgene, Eli Lily, Janssen, Novartis, Pfizer, Merck, UCB, Grant/research support from: Janssen, Novartis

DOI: 10.1136/annrheumdis-2021-eular.1390

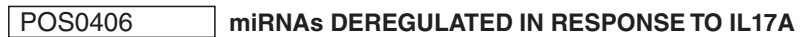 INHIBITORS IN PSORIATIC ARTHRITIS REGULATE GENE PRODUCTS IN Rho-GTPase PATHWAYS}

P. Rahman ${ }^{1}$, Q. Li ${ }^{2}$, D. Codner², D. O'Rielly², A. Dohey², K. Jenkins ${ }^{1}$, D.

D. Gladman ${ }^{3}$, V. Chandran ${ }^{1,3,4}$, I. Jurisica ${ }^{5}{ }^{1}$ Memorial University, Medicine, St.

John's, Canada; ${ }^{2}$ Memorial University, Genetics, St. John's, Canada; ${ }^{3}$ University of

Toronto, Rheumatology, Toronto, Canada; ${ }^{4}$ Krembil Research Institute, UHN, Toronto,

Canada; ${ }^{5}$ Krembil Research Institute, Medical Biophysics, Toronto, Canada

Background: Using transcriptomic data at initiation of therapy, we recently identified differentially expressed genes (DEGs) that separated IL-17Ai response from non-response ${ }^{1}$. Integration of cell-type-specific DEGs with protein-protein interactions (PPIs) and further comprehensive pathway enrichment analysis revealed Rho GTPase signaling pathway exhibited a strong signal specific to IL-17Ai response and particularly the genes, RAC1 and ROCKs.

Objectives: To characterize microRNA ( $\mathrm{miR}$ ) profiles among IL-17Ai responders and non-responders, as it relates to RHO GTPase pathway.

Methods: We interrogated 20 psoriatic arthritis (PsA) patients initiating IL-17Ai. Patients achieving at least low disease activity according to the Disease Activity Index for PsA (DAPSA) at three months were classified as responders. There were seven responders $(35 \%)$ and thirteen non-responders $(65 \%)$ in the IL-17Ai group, with biologic treatment naïve (bio-naïve) and previously-exposed (bio-exposed) patients exhibiting a $50 \%(4 / 8)$ and a $25 \%(3 / 12)$ response rate, respectively. For the miR analysis, CD4 positive $\mathrm{T}$ cells were isolated from peripheral blood mononuclear cells using Dynabeads ${ }^{\mathrm{TM}}$ CD4 beads (ThermoFisher). Total RNA was extracted from the $\mathrm{CD}^{+} \mathrm{T}$ cells using Lexogen's Split RNA Extraction Kit (D-Mark Biosciences). Libraries were prepared from 200ng total RNA with the NEXTFLEX Small RNA-Seq Kit v3 with UDIs (Bioo Scientific) and sequenced on the Illumina NovaSeq 6000 . Raw sequencing fastq data assessed the quality using FastQC. The miRDeep2 was used to trim the adapter, align and quantify human mature miRs from miRbase (Release 22). The abundance of miRs was converted to read counts per million, normalized and limma $\mathrm{R}$ package was used to identify pre- and post-differentially expressed miRs.

Results: We obtained 2,889 miRs. After removing miRs with low reads in $>90 \%$ of samples, 1902 high quality miRs remained for further analysis. Using mirDIP v4.1 we identified gene targets for differential miRs, and focused on recently identified DEGs related to RHO GTPase pathway. The miRs on the left of the figure 1 are those deregulated in pre-treatment, and the miRs on the right of the figure 1

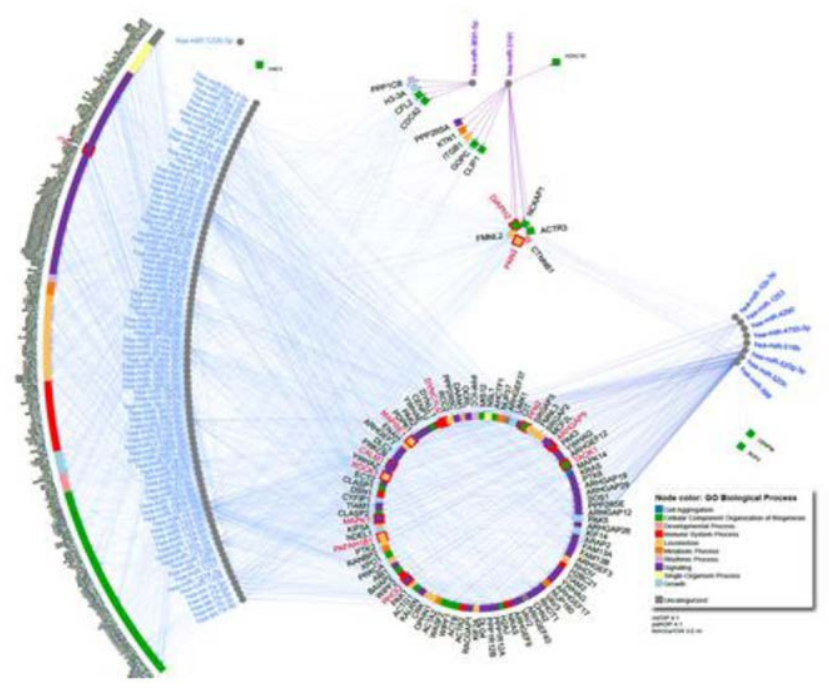

Figure 1.

show the post-treatment deregulated miRs. hsa-miR-3691-5p and hsa-miR-3161 represent the miRs that were deregulated in both conditions. The red highlighted nodes represent the most connected miRs and genes; thus, representing miRs that are the most RHO-pathway centric regulators (hsa-miR-495-3p, 16-5p, $129-5 p, 520 h, 520 g-3 p)$, and genes representing the most strongly regulated RHO-pathway gene products (ROCK1, RHOQ, PFN2, TAOK1, DYNC1L12, MAPRE1, PAFAH1B1, ARHGAP5, MAPK1, CALM1, DIAPH2, PKN2, ITSN1).

Conclusion: Pre- and post-treatment differential miRs related to IL-17Ai response regulate multiple genes from $\mathrm{RHO}$ GTPase pathway. 